J. clin. Path., 1976, 29, 1060-1063

\title{
Purified azure B as a reticulocyte stain
}

\author{
P. N. MARSHALL, S. A. BENTLEY, AND S. M. LEWIS
}

From the Department of Haematology, Royal Postgraduate Medical School, Du Cane Road, London W12 OHS

SYNOPSIS A comparison has been made between reticulocyte preparations stained with purified azure B and with several commercially available batches of brilliant cresyl blue and new methylene blue.

Marked variations were observed in the composition and staining performances of the various $\vec{v}$ batches of the two commercially available dyes. Although there were no significant differences in $\vec{\circ}$ reticulocyte counts obtained with these two dyes, varying amounts of an extraneous, particulate 8 dye deposit were present in these preparations, making accurate counting both tedious and time- $\frac{\rho}{3}$ consuming.

Purified azure B, on the other hand, gave reproducibly stained, deposit-free preparations. Reticulo- $\mathbb{D}$ cyte counts obtained from azure B preparations correlated almost exactly with those determined using new methylene blue. Purified azure B is therefore recommended as a convenient reticulocyte $\frac{\nabla}{\circ}$ stain for routine use.

Although a number of cationic dyes has been used to demonstrate reticulocytes (Nizet, 1944; Vander et al, 1963; Wittekind and Rentsch, 1968), only two are used routinely in haematological practice. These are brilliant cresyl blue (Cesaris-Demel, 1907; Pappenheim, 1907) and new methylene blue (Brecher, 1949) (fig 1). Batch variations in the composition and staining properties of commercial samples of brilliant cresyl blue are well documented (Brecher, 1949; Lillie, 1965; Dacie and Lewis, 1968). New methylene blue is purported to be superior in this respect since less variation has been observed in the visible absorption spectra of different batches (Brecher, 1949; Lillie, 1965). This conclusion is equivocal since such spectra do not always accurately reflect variations in dye composition.

We have therefore devised a reproducible technique employing a cationic dye of constant composition (purified azure B, fig 1) for the staining of reticulocytes.

\section{Material and methods}

Purified azure B was prepared by the method of Marshall and Lewis (1975). The commercial samples of brilliant cresyl blue and new methylene blue are listed in table $\mathrm{I}$.

Received for publication 20 April 1976

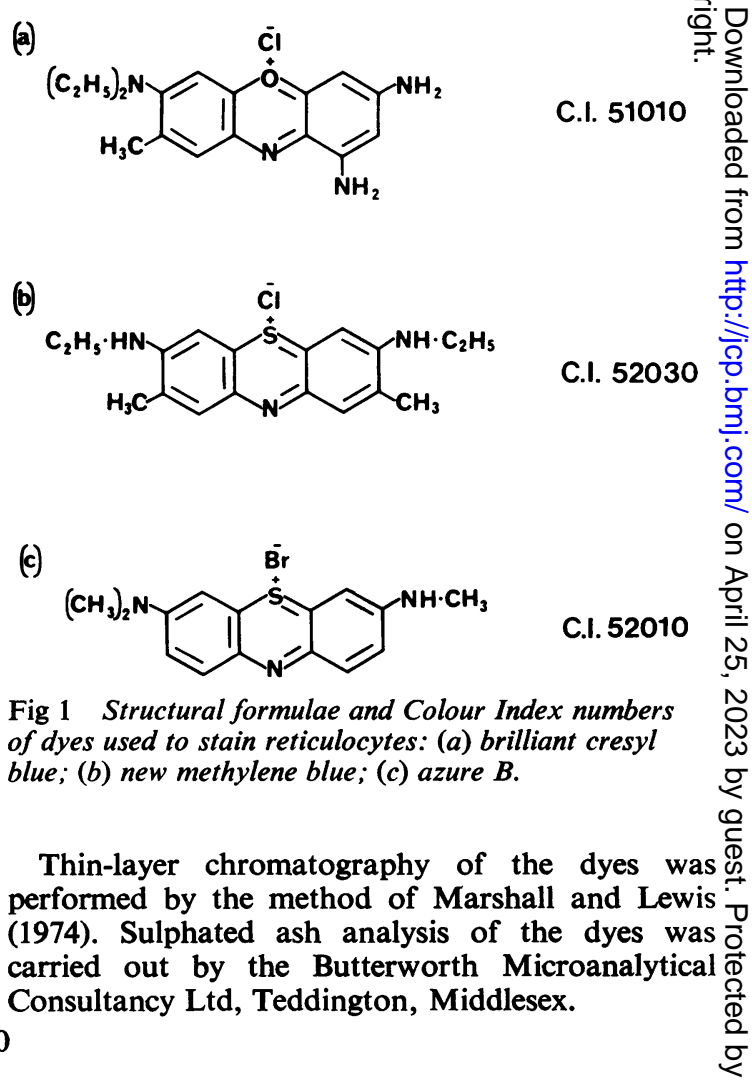




\begin{tabular}{ll}
\hline Dye, supplier, and batch no./purchase date & Sulphated ash (\%) \\
\hline Brilliant cresyl blue & \\
1 G. T. Gurr, 17850 & $13 \cdot 60$ \\
2 G. T. Gurr, 878 & $16 \cdot 12$ \\
3 G. T. Gurr, 0358 & $2 \cdot 62$ \\
New methylene blue & \\
1 BDH, 1190510 & $22 \cdot 52$ \\
2 Eastman, A525744 & $14 \cdot 27$ \\
3 R. A. Lamb, 1047 & $20 \cdot 61$ \\
4 Difco, 0377 & $22 \cdot 86$ \\
5 E. Gurr, purchased 1973 & $9 \cdot 53$ \\
\hline
\end{tabular}

Table I Sulphated ash determinations on commercial samples of brilliant cresyl blue and new methylene blue

Samples of venous blood for reticulocyte staining were collected into EDTA- $\mathrm{K}_{2}$ anticoagulant $(1.5 \mathrm{mg} /$ $\mathrm{ml}$ of blood).

\section{STAINING TECHNIQUE WITH PURIFIED AZURE B}

The stock staining solution is prepared by dissolving $0.5-1.0 \mathrm{~g}$ of azure $\mathrm{B}$ in $100 \mathrm{ml}$ of citrate saline

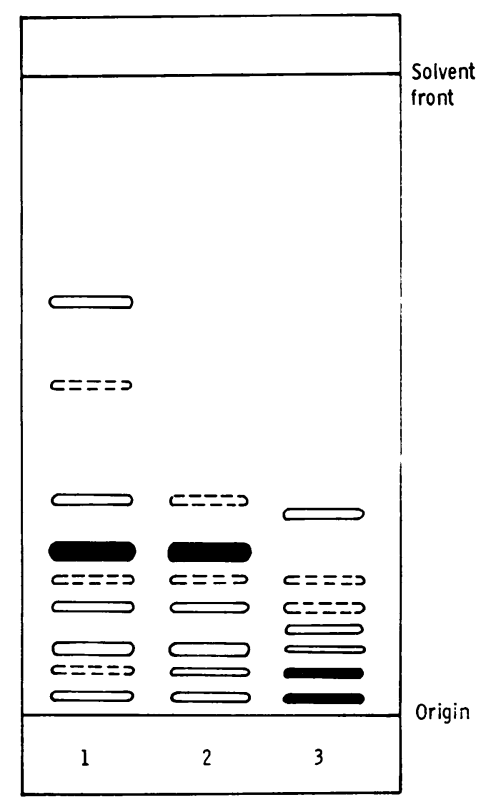

Fig 2 Thin-layer chromatogram of commercially available samples of brilliant cresyl blue. See table I for supplier and batch numbers. All components are blue in colour with the exception of that of highest $R_{f}$ seen in 1 which is purple. Major components are indicated by $\longrightarrow$, trace components by $\subset-=-$, and those present in intermediate amounts by It is not possible to decide which of the many components, if any, corresponds to the nominal dye. solution ( 1 volume of aqueous sodium citrate $(30 \mathrm{~g} / \mathrm{l})$ and 4 volumes of aqueous sodium chloride $(9 \mathrm{~g} / \mathrm{l}))$. This solution is used as in the standard new methylene blue technique described by Dacie and Lewis (1968).

ASSESSMENT OF VARIATIONS IN

APPEARANCES AND RETICULOCYTE COUNTS

OF FILMS STAINED WITH DIFFERENT

BATCHES OF BRILLIANT CRESYL BLUE AND

NEW METHYLENE BLUE

The dye batches listed in table I were used according to the technique described by Dacie and Lewis (1968). A number of blood samples was stained, including normal blood, blood with elevated reticulocyte counts, and blood containing $\mathrm{HbH}$, Heinz bodies, and Howell-Jolly bodies. One thousand reticulocytes were counted from three slides of each specimen (Woolf, 1950).

COMPARISON OF RETICULOCYTE COUNTS OBTAINED WITH NEW METHYLENE BLUE

AND AZURE B TECHNIQUES

In order to compare the reticulocyte counts obtained by the two methods, 12 specimens of blood were

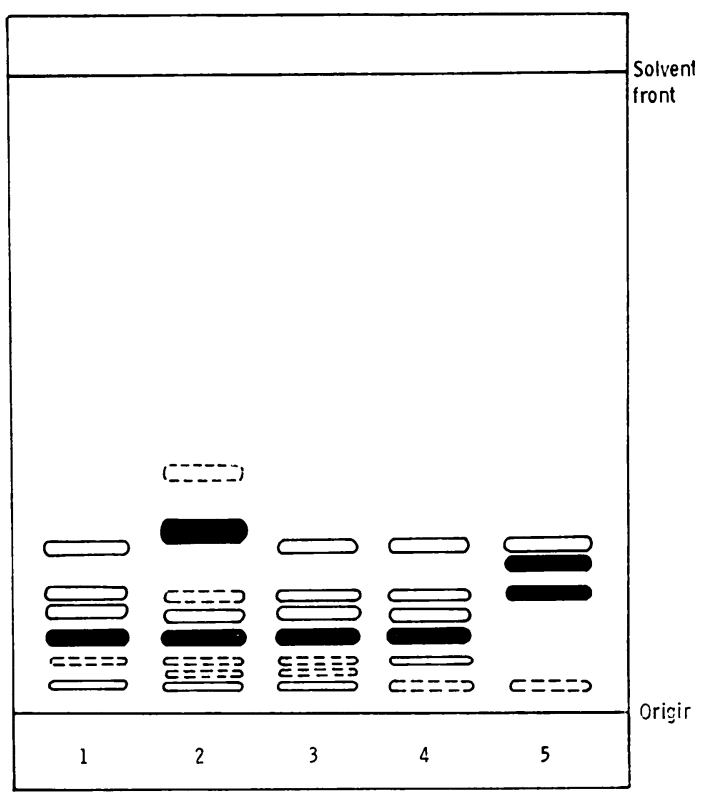

Fig 3 Thin-layer chromatogram of commercially available samples of new methylene blue. See table I for suppliers and batch numbers or purchase date. All components are blue in colour. Major components are indicated by $\longrightarrow$, trace components by and those present in intermediate amounts by Again, it is not possible to ascertain which of the many components, if any, corresponds to the nominal dye. 
selected so as to provide a range of reticulocyte counts. Duplicate preparations were stained with purified azure B and new methylene blue (R. A. Lamb, batch 1047).

\section{Results and discussion}

Thin-layer chromatograms of commercial samples of brilliant cresyl blue and new methylene blue are shown in figs 2 and 3, respectively. Sulphated ash determinations are presented in table I. These dyes were found to be mixtures of varying amounts of several coloured components, and metal salts. 의 Although it is generally held (Brecher, 1949; Lillie, 1965; Dacie and Lewis, 1968) that there is less variation between batches of new methylene blue than those of brilliant cresyl blue, we find no evidence to support this. Samples of purified azure $B$ are constant in composition, being uncontaminated $\vec{\theta}$ with homologous thiazine dyes and only negligibf contaminated with metal salts (Marshall and Lewis 1975).

The appearances of blood stained with various commercially available dyes and purified azure $B$

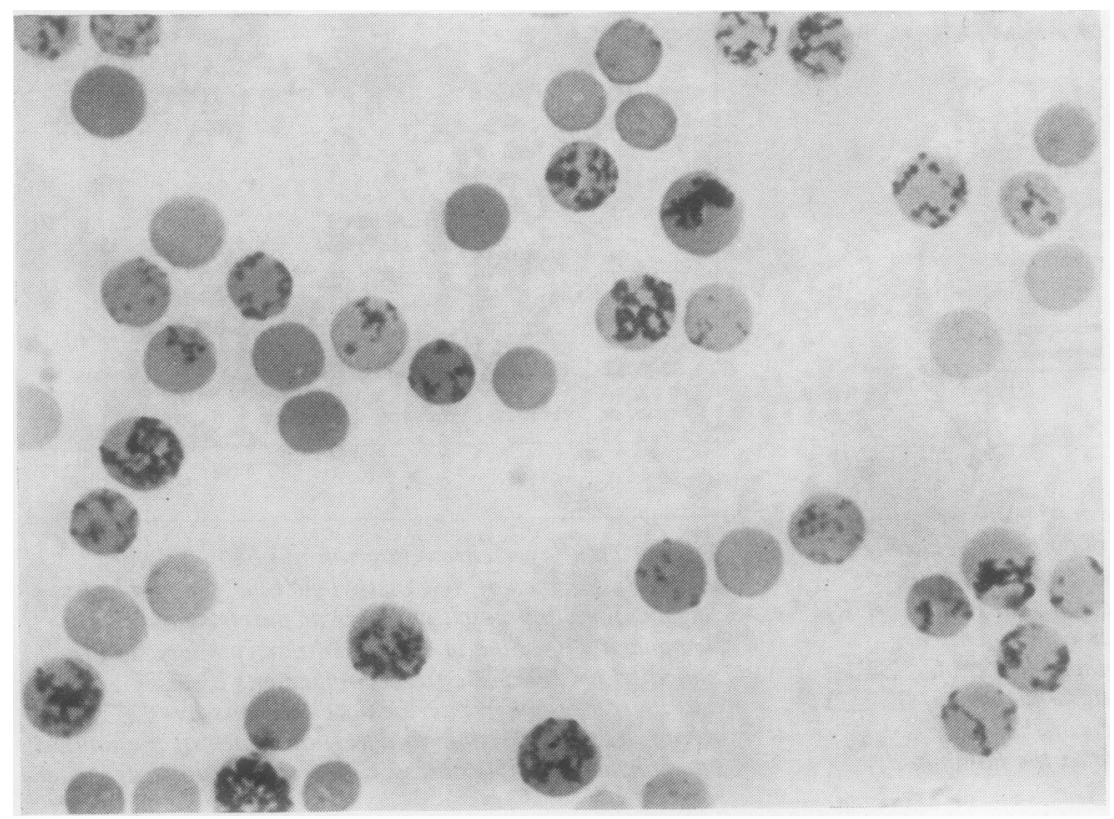

Fig 4 Photomicrograph of reticulocyte film obtained with purified azure $B$. Note the absence of any dye deposit. $\times 1000$ 
are described in table II. It will be noted that all films stained with the commercially available dyes showed a diffusely distributed particulate dye deposit. The reason for this deposit is obscure. It is not merely due to precipitation of dye from a concentrated solution as it is not reduced by considerable reduction of the dye concentration in the stock solution. The presence of deposit over mature red cells is a potential source of counting errors. There were no significant differences between reticulocyte counts from preparations made using the commercial batches of brilliant cresyl blue and new methylene blue which gave countable films, ie, preparations without large amounts of dye deposit. Any dye deposit, however, made accurate counting both tedious and time consuming. Purified azure B gave reproducible, deposit-free preparations (fig 4). The new methylene blue technique was used as the reference method against which the new azure B technique was compared. It was found that reticulo-

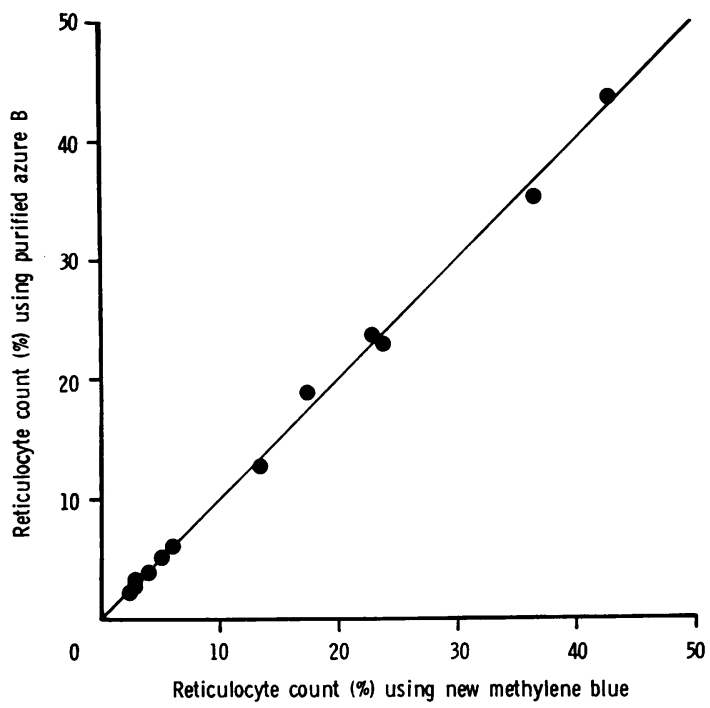

Fig 5 Plot of reticulocyte count as determined using purified azure B technique against that determined using new methylene blue reference method; $Y=0.994 X+0.088: r=0.999$. cyte counts determined with these techniques correlated almost exactly ( $r=0.999)$ (fig 5).

$\mathrm{HbH}$, Heinz bodies, and Howell-Jolly bodies were as well stained by azure $B$ as with the most successful batches of brilliant cresyl blue or new methylene blue.

\section{Conclusions}

Purified azure B is an excellent reticulocyte stain. It has the advantages of reproducibility and absence of dye deposit. These advantages make the stain more convenient for routine use than those currently employed.

This work was supported by a grant to S. M. Lewis from the Department of Health and Social Security. Mr M. Wadsworth provided skilful technical assistance.

\section{References}

Brecher, G. (1949). New methylene blue as a reticulocyte stain. Amer. J. clin. Path., 19, 895-896.

Cesaris-Demel, A. (1907). Studien über die roten Blutkörperchen mit den Methoden der Färbung in frischem Zustande. Fol. haemat. (Lpz.), 4, Suppl. 1, 1-32.

Dacie, J. V. and Lewis, S. M. (1968). Practical Haematology, 4th edition, p. 30. Churchill, London.

Lillie, R. D. (1965). Histopathologic Technic and Practical Histochemistry, 3rd edition, p. 592. McGraw-Hill, New York.

Marshall, P. N. and Lewis, S. M. (1974). A rapid thin-layer chromatographic system for Romanowsky blood stains. Stain Technol., 49, 235-240.

Marshall, P. N. and Lewis, S. M. (1975). The purification of methylene blue and azure $B$ by solvent extraction and crystallization. Stain Technol., 50, 375-383.

Nizet, A. (1944). Recherches sur la physiopathologie des hématies. I. Nouvelles techniques pour l'étude et la distinction des hématies granuleuses. Acta med. scand., 117, 199-215.

Pappenheim. A. (1907). Einige Bemerkungen über Methoden und Ergebnisse der sog. Vitalfärbung an den Erythrozyten. Fol. haemat. (Lpz.), 4, Suppl. 1, 46-49.

Vander, J. B., Harris, C. A., and Ellis, S. R. (1963). Reticulocyte counts by means of fluorescence microscopy. J. Lab. clin. Med., 62, 132-140.

Wittekind, D. and Rentsch, G. (1968). Farbabhängige Strukturvariationen der Substantia granulofilamentosa der Reticulozyten. Blut, 18, 13-21.

Woolf, B. (1950). Labour saving methods in cell counts. Edinb. med. J., 57, 536-546. 